American Journal of Pharmaceutical Education 2018; 82 (9) Article 7271.

\title{
COMMENTARY
}

\section{Is There Room for Efficiency in Pharmacy Education?}

\author{
T. Joseph Mattingly II, PharmD, MBA ${ }^{\mathrm{a}, \mathrm{b}}$ \\ ${ }^{a}$ University of Maryland School of Pharmacy, Baltimore, Maryland \\ ${ }^{\mathrm{b}}$ Editorial Board Member, American Journal of Pharmacy Education, Arlington, Virginia
}

Submitted July 15, 2018; accepted July 19, 2018; published November 2018.

Keywords: tuition, cost, efficiency, economics, education

The industry for educating pharmacists in the United States has grown substantially over the past few decades. ${ }^{1-4}$ The term "industry" seems most appropriate in this context with total pharmacy school revenue approaching \$3.8 billion in the US (estimated from 131 fully accredited programs and a mean annual revenue of $\$ 29$ million/program reported in 2017). ${ }^{5}$ While these revenues are obtained from a diverse portfolio of sources (public funding, tuition and fees, endowment income, gifts, research funding, and other miscellaneous income), schools report approximately $44 \%$ of total revenue comes from student tuition and fees. ${ }^{5}$

The tuition trend data, published by the American Association of Colleges of Pharmacy (AACP), provides insights into how tuition and fees for both in-state and out-of-state students have changed over time. ${ }^{5}$ Since 2004, an overwhelming majority of pharmacy schools have increased student costs at a rate much faster than inflation (Figure 1). During this same time, over 90\% $(74 / 82)$ of schools reported an increase in the number of Doctor of Pharmacy (PharmD) degrees conferred (Figure 2) with eight schools more than doubling their class sizes. The pharmacy education industry responded to market dynamics with an increasing consumer (student) demand and capitalized on the willingness-to-pay of tens of thousands of students aided by expanding student loan subsidies. However, we now find ourselves in a situation where recent graduates are worse off than similar cohorts from just a few years ago as the discretionary income for pharmacists has not kept pace with student debt loads. ${ }^{6}$

The industry thought leaders must grapple with a decrease in consumer demand as potential pharmacy school applicants may pursue alternate career paths where the cost-benefit ratio is more promising. Improving the value proposition for the best students must go beyond maintaining a positive net present value estimate for

Corresponding Author: Joey Mattingly, 20 N. Pine St., N415, Baltimore, MD 21201. Tel: 410-706-8068. E-mail: jmattingly@rx.umaryland.edu obtaining a PharmD degree. ${ }^{7}$ Assuming the value of obtaining a PharmD could be estimated as a function of all costs and benefits, industry leaders have the ability to influence both variables to varying degrees. While the benefits of becoming a pharmacist continue to evolve as the profession advances, the cost side of the equation is more malleable and the focus of this perspective.

\section{Direct Costs of Obtaining a PharmD}

As with many costs analyses, it is easier to start with the direct costs as they are typically more objective and easier to capture with real world evidence. Chisholm-Burns and colleagues used multiple direct cost components from the perspective of a potential PharmD student to estimate the value and break-even when obtaining the PharmD compared with high school and bachelor degree graduates. ${ }^{7,8}$ Capturing both tuition and cost of living are important for educators to keep in mind that even reducing a school's tuition may not be enough in cases when the housing market or other basic living expenditures experience periods of high inflation. ${ }^{6}$

The price of tuition may be the most important variable for industry leaders to focus on, as it may be one of the only cost variables we can actually influence in both the short and long runs. Cain and colleagues described multiple financial pressures facing institutions, including reduced government support of higher education, increased administrative burden, accreditation costs, and the demand for more elaborate facilities and other amenities to attract students and faculty. ${ }^{9}$ The extent to which industry leaders can influence tuition charges may be affected by the institution type or other factors at the university level. In some cases, pharmacy administrators may feel more like "price takers" as the tuition decision may occur in the provost, president, or chief executive offices. With that said, pharmacy school deans, faculty, and alumni all may be able to influence tuition decisions through various mechanisms. 


\section{American Journal of Pharmaceutical Education 2018; 82 (9) Article 7271.}



Figure 1. Distribution of 2016 In-State Tuition and Fees as a Function of 2004 In-State Tuition and Fees Among the 87 Pharmacy Schools and Colleges That Are Included in the AACP Office of Institutional Research \& Effectiveness Tuition Trends Report. ${ }^{5}$

Another direct cost component for students that was addressed by Cain and colleagues included student loan interest rates, which have risen substantially. ${ }^{9}$ Education industry leaders have much less influence on federal loan interest rate decisions compared with tuition charges. However, financing mechanisms should still be a topic of discussion at AACP meetings as many of our association leaders and pharmacy faculty are savvy mathematicians and statisticians. Why couldn't we tackle the actuarial challenge of student loan financing and seek to offer financing options with much better terms and rates compared with existing federal and private options?

\section{Indirect Costs of Obtaining a PharmD}

Estimating the impact of indirect costs is extremely challenging, and, in the case of pharmacoeconomics, often leads to a disclaimer explaining why a societal perspective was not included in a cost-effectiveness analysis.
When thinking about all the potential indirect costs of obtaining a PharmD from the student perspective, time may be the most important variable to consider because it may be broken into several different variables. For example, the time one spends in class may be different than the time one needs to study outside of the classroom to be successful. For students with children, the additional burden of a spouse or relative to assume caregiver responsibilities may be a substantial cost consideration.

The opportunity costs of pursuing a different career path should always be on the minds of pharmacy education industry leaders. Many high school students employ the strategy of completing the pre-requisites for multiple health science-focused doctoral programs (medicine, dentistry, nursing, pharmacy, physical therapy, etc.). After achieving good grades and high entrance examination scores, pre-health science students may reassess how competitive their applications are for each of the

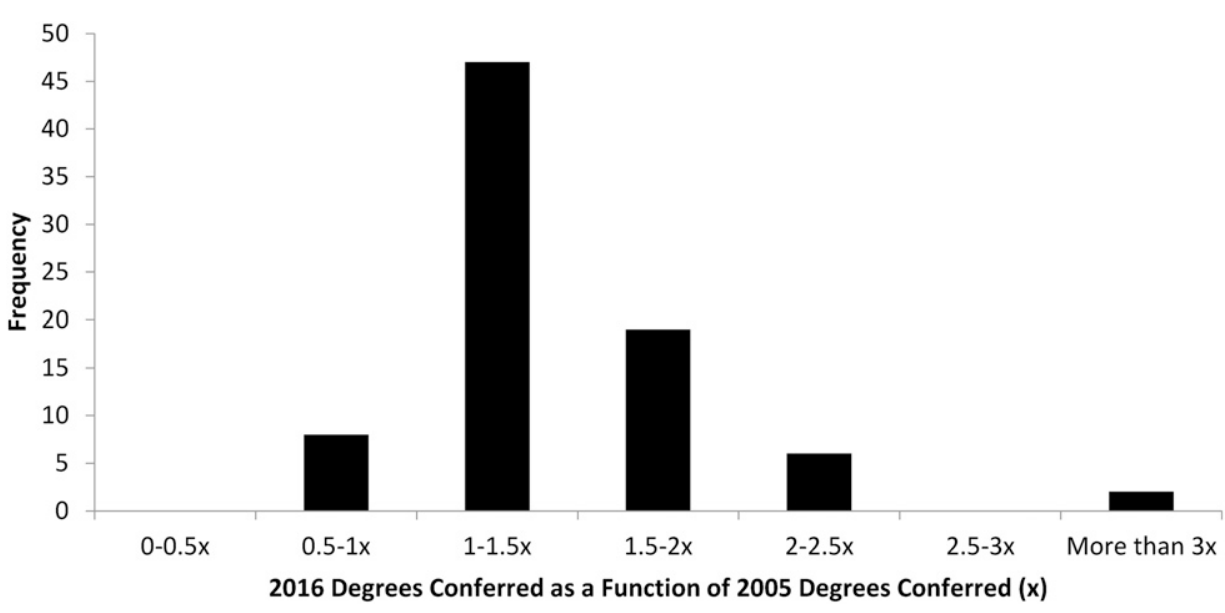

Figure 2. Distribution of 2016 PharmD Degrees Conferred as a Function of 2005 PharmD Degrees Conferred Among 82 Pharmacy Schools and Colleges That had Graduates in Both 2005 and 2016. ${ }^{5}$ 


\section{American Journal of Pharmaceutical Education 2018; 82 (9) Article 7271.}

programs of interest. After gaining some experience as an employee or volunteer, students may have a better idea of their personal rankings of health professional career paths. So, estimating an average opportunity cost of not attending medical school for a PharmD student may not be helpful. Instead, we could evaluate the changing value propositions for each of the professional pathways in health care. For example, evaluating costs (tuition, cost of living, interest rates, time to complete degree) and benefits (salary, job satisfaction, advancement opportunities) for prospective physicians, dentists, nurses, physical therapists and pharmacists over time could help us identify when the value of becoming a pharmacist begins to trend in the wrong direction. While this would not give us an exact representation of the total opportunity cost, it would enable us to account for a confounder that is often missed when only focusing on the pharmacy education market.

\section{How Can Efficiency Help Pharmacy Education?}

All industries face financial pressures in some form and competitors within the market typically innovate to offer differentiated products at a premium price, focus on a niche market, or produce products more efficiently to lower prices. ${ }^{10}$ I would argue that pharmacy schools spend too much time focusing on niche markets or other differentiation strategies and too little time on price leadership strategies. One of the major barriers to entry for a company new to a market is the "economies of scale" that older and larger businesses typically possess, making it difficult for the new company to compete at low prices. ${ }^{10}$ When an influx of schools entered the pharmacy education market in the mid-2000s, established schools did not respond by lowering prices and exerting their competitive advantage of producing PharmDs at a much lower unitprice. Instead, prices for students inflated and established schools focused on differentiating themselves from the newer market entrants by capitalizing on school "brands" and other intangible assets (alumni networks, existing health-system affiliations, etc.).

Efficiency can be a scary proposition, especially considering how terms such as "lean" conjure images of laid-off employees. A shift toward efficiency may not focus solely on reducing the size of the workforce. However, it would require a real commitment to produce high quality PharmD graduates with fewer total resource inputs, which may include less administrative overhead, more reliance on technology and automation, or smaller pharmacy school buildings sans the Roman Colosseumesque extravagance. Cain and colleagues described the potential "arms race" that may arise from competitive recruitment for students, making it even more daunting for a school to begin cutting back for fear of losing prospective students to institutions with all the amenities. ${ }^{9}$ I believe a school moving to become a price leader in pharmacy education could attract more than enough high quality applicants if they can successfully demonstrate that graduates will finish school well under the six-figure debt estimates for most schools. The school would need to effectively communicate that affordability and quality are not mutually exclusive, as low cost sometimes carries a negative connotation (eg, cheap or generic).

This commentary is not meant to advocate the sole focus on lowering the costs as we all strive to produce high quality health care professionals to uphold our oath. ${ }^{11}$ Instead, please consider this a call to evaluate alternative strategies that incorporate efficiency to address the burdens facing current and future students to maintain a strong and vibrant industry.

\section{REFERENCES}

1. Grabenstein JD. Trends in the numbers of US colleges of pharmacy and their graduates, 1900 to 2014. Am J Pharm Educ. 2016;80(2):Article 25.

2. Knapp DA, Knapp DE. Attributes of colleges and schools of pharmacy in the United States. Am J Pharm Educ. 2009;73(5):Article 96.

3. DiPiro JT. Is the quality of pharmacy education keeping up with pharmacy school expansion? Am J Pharm Educ. 2003;67(2):Article 48.

4. Brown DL. A looming joblessness crisis for new pharmacy graduates and the implications it holds for the academy. Am J Pharm Educ. 2013;77(5):Article 90.

5. AACP - Office of Institutional Research \& Effectiveness. Institutional research. American Association of Colleges of Pharmacy. https://www.aacp.org/research/institutional-research. Published 2018. Accessed July 8, 2018.

6. Mattingly TJ, Ulbrich TR. Evaluating the changing financial burdens for graduating pharmacists. Am J Pharm Educ. 2017;81(7): Article 5990.

7. Chisholm-Burns MA, Gatwood J, Spivey CA. Economic analysis of obtaining a PharmD degree and career as a pharmacist. $A m J$ Pharm Educ. 2015;79(8):Article 117.

8. Chisholm-burns MA, Gatwood J, Spivey CA, Dickey SE. Break-even income analysis of pharmacy graduates compared to high school and college graduates. Am J Pharm Educ. 2016;80(3): Article 44.

9. Cain J, Campbell T, Congdon B, et al. Complex issues affecting student pharmacist debt. Am J Pharm Educ. 2014;78(7):Article 131. 10. Porter ME. Competitive Strategy: Techniques for Analyzing Industries and Competitors. New York, NY: Simon \& Schuster, Inc.; 1980.

11. American Association of Colleges of Pharmacy. The oath of a pharmacist. https://www.aacp.org/sites/default/files/2018-05/ oath2018.pdf. Published 2007. Accessed July 14, 2018. 